\title{
Cancer-related fatigue: impact on patient quality of life and management approaches
}

\author{
This article was published in the following Dove Press journal: \\ Nursing: Research and Reviews \\ 9 July 2015 \\ Number of times this article has been viewed
}

\author{
Theresa Pluth Yeo ${ }^{1,2}$ \\ Shawnna Cannaday' \\ 'Thomas Jefferson University Hospital, \\ Department of Surgery Thomas \\ Jefferson University, ${ }^{2}$ Jefferson College \\ of Nursing, Philadelphia, PA, USA
}

\begin{abstract}
Cancer-related fatigue is a common and distressing symptom that is present in the majority of cancer patients at some point during the disease course. Cancer-related fatigue has a profound influence on patients, affecting functional performance, mood, and one's overall quality of life. The etiology of cancer-related fatigue is multifactorial, involving a complex interplay of biological and body system factors. All cancer patients should be screened for fatigue, as it often coexists with other symptoms and its side effects may be underdiagnosed. Treatment modalities for cancer-related fatigue are still evolving. Current recommendations for management from national and international cancer experts and societies focus on patient and family education regarding cancer-related fatigue, exercise and physical activity, and psychosocial interventions. Pharmacologic interventions are less effective but may be helpful in a selected subset of affected individuals.
\end{abstract}

Keywords: evidence based practice, CRF, disease management, quality of life, exercise

\section{Introduction and background}

The American Cancer Society estimates that there will be 18 million cancer survivors in the United States alone by 2022. ${ }^{1}$ The traditional definition of a cancer survivor is any living person who has ever received a diagnosis of cancer, beginning at the time of diagnosis until the end of life is reached. ${ }^{2}$ Recognizing that survivorship is a multistage process with acute, extended, and permanent phases, patients in the cancer journey experience a plethora of symptoms and therapy-related side effects. One of the most prevalent symptoms is cancer-related fatigue (CRF). The National Comprehensive Cancer Network (NCCN) defines CRF as "a distressing, persistent, subjective sense of physical, emotional, and/or cognitive tiredness or exhaustion related to cancer or cancer treatment that is not proportional to recent activity and interferes with usual functioning." ${ }^{3}$ CRF was accepted by the International Classification of Diseases, Tenth Revision, Clinical Modification in 1999; this acceptance has improved the ability to characterize the incidence and prevalence of the condition. ${ }^{4} \mathrm{CRF}$ is typically not relieved simply by rest and this distinguishes it from many non-cancer-related forms of fatigue. ${ }^{5} \mathrm{CRF}$ is caused by the cancer itself and is present in the majority of patients at the time of the cancer diagnosis. CRF often persists following cancer surgery and may intensify during chemotherapy and radiation therapy, morphing into cancer therapyrelated fatigue. A number of studies have documented that fatigue occurs in 30\%-70\% of all patients at some point during the cancer journey ${ }^{6}$ and that it may continue after cancer treatment has been completed. This wide variation may represent differences in how fatigue is defined and the measurement tool used. The incidence of CRF in
Correspondence: Theresa Pluth Yeo Jefferson Department of Surgery, 1025 Walnut Street, Suite 605B, College Building, Philadelphia, PA 19107, USA Tel +l 2I5955 5542

$\mathrm{Fax}+\mathrm{I} 2159236609$

Email theresa.yeo@jefferson.edu 
survivorship cohorts is reported to be between $10 \%$ and $30 \%$. $^{7}$ In patients with metastatic disease, the prevalence of CRF exceeds $75 \% .^{3}$ The etiology of CRF is multifactorial, with varying degrees of contribution from biological cancer factors, cancer treatment, immune system dysregulation, hypothalamic-pituitary-adrenal axis dysfunction, secondary anemia, opioid medications, anorexia/cachexia, poor sleep quality, and cognitive dysfunction. ${ }^{8-10} \mathrm{CRF}$ affects one's perceived overall quality of life by impacting physical, functional, and cognitive domains.

The current recommendations for management of CRF include: patient and family education, self-care, nonpharmacologic interventions, and pharmacologic treatment..$^{311-14}$ Several systematic reviews have indicated that the effectiveness of pharmacologic regimens is limited and that nonpharmacologic interventions are moderately effective. ${ }^{15,16}$ The purpose of this article is to review the current knowledge about CRF and cancer therapy-related fatigue and to discuss the evidence regarding best practices for their management.

\section{Impact on quality of life}

Cancer therapy-related side effects are well documented and include: chest pain, nausea/vomiting, stomatitis, diarrhea, constipation, fever, fatigue, anorexia, dyspnea, dermatitis, neurosensory or motor problems, bleeding, palmar-plantar syndrome, pain, bruising and extravasation, as well as other less common side effects. ${ }^{17}$ The presence of any or a combination of these side effects can have a detrimental effect on one's well-being, body image, and self-perception. CRF is often reported as the most distressing symptom ${ }^{18}$ while pain is the most feared side effect of cancer therapy. Although fatigue and a lack of energy are frequently reported by cancer patients and cancer survivors, the impact on one's quality of life had not been well described in a large patient sample until the 1996 Fatigue Coalition ${ }^{6}$ reported on the functional impact of CRF. The impact of CRF on physical, psychosocial, and economic and occupational domains was further evaluated in the 2000 Fatigue Coalition follow-up survey. ${ }^{6}$ Diminished energy levels, needing to slow down, and a subjective sense of tiredness were reported by $80 \%$ of the respondents. ${ }^{6}$ The survey also sought to elucidate the psychosocial effects of cancer therapy. Patients commonly reported decreased overall motivation, needing to push oneself, and feeling sad, frustrated, and irritable. Cognitive function was also affected, manifested as decreased concentration, trouble with memory, and difficulty keeping dates straight. Patients who were still employed were absent from work 4.2 days per month, during and after treatment had ended. ${ }^{6}$ Patients identified the following activities as the most difficult: walking distances, doing household chores, cleaning the house, socializing, and preparing food. In a separate investigation, Lis et al found that increasing CRF was an independent predictor of overall dissatisfaction with life. ${ }^{19}$ Those individuals reporting fatigue levels in the severe range (7-10/10) were least likely to feel satisfied with life (odds ratio $0.28,95 \%$ confidence interval: $0.09-0.91, P=0.03$ ).

\section{Therapy-related fatigue}

Estimates of the occurrence of cancer therapy-related fatigue vary from $30 \%$ to $91 \%$ in patients receiving chemotherapy, $25 \%$ to $83 \%$ in patients receiving radiation therapy, and $59 \%$ to $83 \%$ in patients undergoing combined chemo- and radiation therapy. ${ }^{6}$ The use of different chemotherapeutic agents and regimes may account for some of this variance. When patients were queried about the most bothersome side effects of chemotherapy, nausea was first (34\%), followed by fatigue $(18 \%)$, with hair loss third $(11 \%) .{ }^{6}$ However, when asked which side effect had the greatest impact on their life after completion of therapy, fatigue was number one, with $54 \%$ reporting fatigue that lasted more than 2 weeks after the completion of chemotherapy. ${ }^{6}$ CFR may linger after cancer treatments have been completed, being reported for up to a year in many cancer survivors.

\section{Management principles in CRF}

$\mathrm{CRF}$ has been underappreciated as a common and persistent symptom of cancer and cancer treatment. Health care providers often underestimate the frequency and intensity of CRF and feel challenged in treating it. ${ }^{20}$ James et al conducted two surveys of cancer patients undergoing either radiation therapy or chemotherapy. In Survey 1, 29 patients reported experiencing fatigue during treatment, but only two received any advice on managing CRF. In Survey 2, which included 148 patients, $86 \%$ stated that they were advised about the risk of CRF; however, only $67 \%$ were assessed at their visit or were given recommendations for $\mathrm{CRF}^{20}$

In the Fatigue Coalition survey, physicians were given recommendations for treating $\mathrm{CRF}^{6}{ }^{6}$ The standard of care in CFR has been set forth by the NCCN and includes recognition that fatigue is a complex entity, typically occurring in conjunction with pain, insomnia, anxiety, distress, and, often, anemia, as part of defined symptoms clusters (Table 1). ${ }^{3,21}$ The NCCN, the Oncology Nursing Society (ONS), the American Society of Clinical Oncology (ASCO), and the Pan-Canadian Practice Guideline ${ }^{10}$ provide evidence-based guidelines for the management of CRF and cancer therapyrelated side effects. These four guidelines are generally congruent in their recommendations, though some variations 


\section{Table I NCCN CRF Standard of Care overview}

- Assess fatigue at initial encounter and evaluate for systemic causes.

- Reassess fatigue at regular intervals during cancer treatment and after treatment has ended.

- Manage fatigue according to established clinical guidelines.

- Patients and their families should be aware that CRF management is an integral part of cancer care.

Notes: Adapted from Berger AM, Abernethy AP, Atkinson A, et al. Cancer-related fatigue. J Natl Compr Canc Netw. 2010;8(8):904-931. ${ }^{3}$ To view the NCCN complete Standard of Care for CRF, see Berger et al. ${ }^{3}$

Abbreviations: CRF, cancer-related fatigue; NCCN, National Comprehensive Cancer Network.

do exist. Managing CRF requires a coordinated effort by all members of the health team including physicians, nurses, advanced practice nurses, social workers, physical therapists, cancer rehabilitation specialists, nutrition support teams, and mental health providers. The basic recommendations for CRF intervention include ongoing assessment; nonpharmacologic interventions, including patient and family education on CRF and self-care strategies; and pharmacologic treatment ${ }^{3-14}$ and will be discussed in the following sections (Figure 1).

\section{Ongoing patient assessment}

All cancer patients should be screened for CRF at their initial health care encounter in order to establish a baseline and at subsequent visits to monitor trends. Many cancer care practitioners consider fatigue as the sixth vital sign, following temperature, pulse, blood pressure, respirations, and pain level. A numeric rating scale $(0=$ none to $10=$ worst $)$

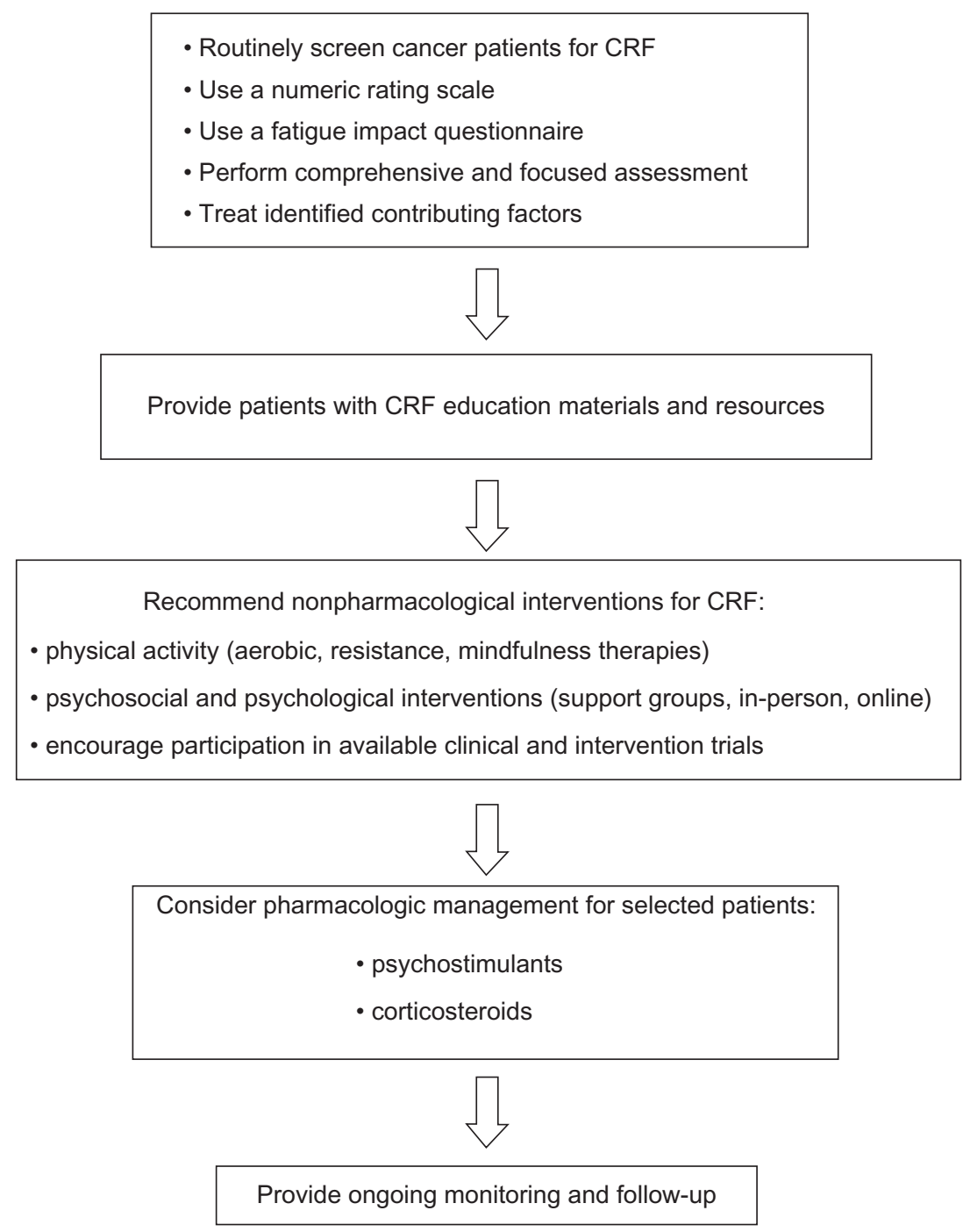

Figure I Guidelines for management of CRF.

Notes: Adapted from NCCN Clinical Practice Guidelines. Cancer-Related Fatigue. Version 1.2014. Available from: http://www.nccn.org/professionals/physician_gls/pdf/fatigue.pdf. Accessed January 25, 2015. ${ }^{2}$ And from Mitchell SA, Clark JC, DeGennaro RM, et al. Fatigue [webpage on the Internet]. Pittsburgh: Oncology Nursing Society; 20I I-20 I4. Available from: http://www.ons.org/practice-resources/pep/fatigue.Accessed January 26, 2015.14

Abbreviation: CRF, cancer-related fatigue. 
is considered a valid screening and monitoring tool and is recommended by the NCCN (Table 2). ${ }^{3,12}$ Research has shown that the fatigue score of $7 / 10$ or higher is a significant break point in that it correlates with a marked decrease in physical functioning. ${ }^{22}$ The initial encounter should include a clinical assessment and physical examination of the patient to determine other possible underlying causes for CRF or conditions that will aggravate CRF. Clinically evident expressions of CRF may include: weakness, diminished mental capacity, insomnia or hypersomnia, and emotional lability. ${ }^{23}$ The evaluation should include consideration of the disease stage, evidence of disease spread or recurrence, current and past treatment received (both for cancer and psychiatric disorders), current medications, over-thecounter preparations, herbal remedies used, and a review of associated symptoms such as pain, depression, anxiety, sleep disturbance, shortness of breath, change in appetite, and assessment of alcohol or substance misuse. ${ }^{3,11,13}$ The provider should also assess for the presence of comorbidities that could contribute to CRF, including: cardiac dysfunction, pulmonary disease, anemia or pancytopenia, renal or liver failure, psychological conditions, neurological problems, and endocrine disease (diabetes, thyroid disorders, or adrenal insufficiency. ${ }^{3,13} \mathrm{~A}$ fatigue-specific assessment tool which is reliable and well validated such as the FACITFatigue Scale, ${ }^{22}$ the Brief Fatigue Inventory, ${ }^{23}$ the Piper Fatigue Scale, ${ }^{24}$ or the European Organization of Research and Treatment-Related Quality of Life Core Questionnaire (EORTC-QLC30), ${ }^{25}$ among others, should be used to document fatigue frequency and intensity in a standardized fashion (Table 3) ${ }^{26,27}$ The Medical Outcomes Short-Form 36 or $12,{ }^{28,29}$ or the Eastern Cooperative Oncology Group (ECOG) Performance Status rating scale, ${ }^{30}$ are acceptable to use in combination with a fatigue-intensity tool (ie, numeric rating scale) ${ }^{31}$ to document the effect of CRF on health-related quality of life. The Medical Outcomes ShortForm 36 assesses eight domains: cognitive functioning, sleep, health distress, social support, family and marital functioning, sexual functioning, physical symptoms, and psychological symptoms ${ }^{28}$ while the ECOG scale is a more general measure of functional capacity. ${ }^{30}$

Table 2 Fatigue numeric rating scale $(0-10)$

- $0=$ no fatigue

- I, 2, 3= mild fatigue

- $4,5,6=$ moderate fatigue

- 7, 8, 9, $10=$ severe fatigue

Note: Reproduced from Berger AM, Abernethy AP, Atkinson A, et al. Cancerrelated fatigue. J Natl Compr Canc Netw. 2010;8(8):904-931. ${ }^{3}$

\section{Nonpharmacological interventions}

A number of systematic reviews have concluded that nonpharmacological interventions are effective in reducing CRF both alone and in combination with selected pharmacologic therapies. ${ }^{32}$ Nonpharmacologic interventions for the management of CRF are varied and include home-based and supervised exercise, patient and family education and psychological and psychosocial therapy, distracting activities, complementary therapies, and nutritional counseling.

\section{Exercise/physical activity}

Replacing the word "exercise" with, simply, the word "movement" may be less intimidating to cancer patients, many of whom (like $75 \%$ of adult Americans) are not regular exercisers. ${ }^{33}$ Movement is defined as any bodily activity produced by skeletal muscle contraction that increases energy use above the baseline level and requires tissue oxygenation. ${ }^{7}$ Planned, structured, and repetitive body movement has been found in a number of patient populations to decrease CRF, improve mood, and increase one's functional capability. The ONS's Putting Evidence into Practice (PEP) guidelines were updated in 2014. ${ }^{34}$ Physical activity/exercise/movement are termed "effective" in reducing CRF in more than 40 metaanalyses and randomized controlled trials (RCTs). The populations included in the studies included patients with varied cancer types and patients undergoing treatment utilizing radiation, chemotherapy, or hematopoietic stem cell transplantation. ${ }^{34}$ A 2012 Cochrane Review of exercise for the management of CRF considered 56 published RCTs on the topic. ${ }^{35}$ The study samples included patients with breast, prostate, colorectal, head, and neck cancers and hematologic malignancies, although the majority of the studies were performed in breast cancer patients. A significant improvement in CRF was found with aerobic exercise programs but not for resistance training or mind-body techniques. Lack of long-term follow-up regarding exercise maintenance and insensitive outcome measures may have limited the ability to detect individual benefits from the programs. ${ }^{36}$ None of the studies included biomarkers (proinflammatory cytokines) of the interrelated pathways of fatigue, such as the inflammatory, nervous system, metabolic and hypothalamic-pituitaryadrenal axis. Correlating this data will allow the development of strategies and pharmacologic treatments that more specifically target the offending pathway. No study in the Cochrane Review reported complications, such as falls or dizziness that were related to the exercise regimen. ${ }^{35}$ It is possible that the occurrence of adverse events contributed to patients dropping out of the studies or failing to complete the program. Patients with comorbid conditions that would limit physical 
Table 3 Summary of selected fatigue and quality-of-life assessment tools

\begin{tabular}{|c|c|c|c|}
\hline Name of tool and description & Reliability and validity & $\begin{array}{l}\text { Typical } \\
\text { completion time }\end{array}$ & Advantages of tool \\
\hline $\begin{array}{l}\text { Fatigue Visual } \\
\text { Numeric rating scale. } \\
\text { Single item asks severity of fatigue at } \\
\text { the present time rated on a } 0-10 \text { rating } \\
\text { scale where } 0=\text { no fatigue and } 10=\text { worst } \\
\text { possible fatigue. }\end{array}$ & $\begin{array}{l}\text { - Useful for obtaining ordinal } \\
\text { preferences. } \\
\text { - Prone to bias when used as the } \\
\text { only measure of fatigue. }\end{array}$ & $<I$ minute & $\begin{array}{l}\text { - One-dimensional measure of fatigue. } \\
\text { - Use only as a screening tool. } \\
\text { - Provides serial monitoring of fatigue } \\
\text { severity. } \\
\text { - Best used in conjunction with an in- } \\
\text { depth fatigue or symptom questionnaire. }\end{array}$ \\
\hline $\begin{array}{l}\text { FACIT-Fatigue Scale. }{ }^{22} \text { Thirteen-item } \\
\text { fatigue subscale of the FACT-F tool. } \\
\text { Developed in } 1997 \text { from } 32 \text { items } \\
\text { submitted by five medical experts and } \\
221 \text { items from } 14 \text { cancer patients. }\end{array}$ & $\begin{array}{l}\text { Reliability: high test-retest reliability, } \\
r=0.87 \text {. } \\
\text { Internal consistency: } \alpha=0.93-0.95 \text {. }\end{array}$ & $<5$ minutes & $\begin{array}{l}\text { - Independent, one-dimensional measure } \\
\text { of fatigue. } \\
\text { - Asks patients to consider fatigue in } \\
\text { context of last } 7 \text { days. }\end{array}$ \\
\hline $\begin{array}{l}\text { Revised Piper Fatigue Scale. }{ }^{24} \\
\text { Twenty-two-item questionnaire that } \\
\text { assesses four subscales (behavioral/ } \\
\text { severity, affective meaning, sensory, and } \\
\text { cognitive/mood). }\end{array}$ & $\begin{array}{l}\text { Reliability: } r=0.30-0.70 \text {. } \\
\text { Internal consistency: } \alpha=0.97 \text {. }\end{array}$ & $\sim 10-15$ minutes & $\begin{array}{l}\text { - Multidimensional measure of fatigue. } \\
\text { - Allows accurate measurement and } \\
\text { cancer-related fatigue interventions. }\end{array}$ \\
\hline $\begin{array}{l}\text { Medical Outcomes Study SF- } 36 .^{28} \\
\text { Thirty-six-item questionnaire that address } \\
\text { eight domains (cognitive functioning, sleep, } \\
\text { health distress, social support, family and } \\
\text { marital functioning, sexual functioning, } \\
\text { physical symptoms, and psychological } \\
\text { symptoms). }\end{array}$ & $\begin{array}{l}\text { Reliability: } r=0.8-0.93 \text {. } \\
\text { Internal consistency: } \alpha \geq 0.70 \text {. }\end{array}$ & $\sim 10-15$ minutes & $\begin{array}{l}\text { - Valid and reliable multipurpose general } \\
\text { health survey. } \\
\text { - In addition to the eight domains } \\
\text { assessed, two psychometrically } \\
\text { based composite scores, PCS and } \\
\text { MCS, are generated when using the } \\
\text { Quality Metric }{ }^{\mathrm{TM}} \text { Scoring Software. } \\
\text { These scores are considered a valid } \\
\text { representation of health-related quality } \\
\text { of life. }\end{array}$ \\
\hline $\begin{array}{l}\text { Medical Outcomes } \\
\text { Study SF-I } 2 .{ }^{29} \text { Twelve-item } \\
\text { multidimensional assessment of general } \\
\text { health. Derived from the SF- } 36 \text {. }\end{array}$ & $\begin{array}{l}\text { Reliability: } R^{2}=0.91-0.92 \\
\text { Internal consistency: } \alpha=0.93-0.98 \text {. }\end{array}$ & $\sim 2$ minutes & $\begin{array}{l}\text { - Shorter than the SF- } 36 \text {. } \\
\text { - Retains accuracy of the PCS and MCS } \\
\text { composite scores. } \\
\text { - Precision increases with large sample } \\
\text { sizes. } \\
\text { - Correlations between SF- } 12 \text { and SF-36 } \\
\text { versions of PCS and MCS were } 0.95 \\
\text { and } 0.97 \text {. }\end{array}$ \\
\hline $\begin{array}{l}\text { ECOG Performance Status rating } \\
\text { scale. }{ }^{30,70,71} \text { The ECOG scale is a six-level } \\
\text { assessment tool that provides a measure } \\
\text { of physical functioning by determining the } \\
\text { degree to which cancer patients are able } \\
\text { to participate in activities of daily living, } \\
\text { and their need for rest during the day. }\end{array}$ & $\begin{array}{l}\text { - Considered to have moderate } \\
\text { reliability and validity. } \\
\text { - When compared head-to-head } \\
\text { with the Karnofsky Performance } \\
\text { Status scale, in a sample of patients } \\
\text { with lung cancer, the ECOG scale } \\
\text { had better prognostic ability. } \\
\text { Reliability: } r=0.75, P<0.00-I \text {. } \\
\text { Internal consistency: } \alpha=0.6 \text {. }\end{array}$ & $<2$ minutes & $\begin{array}{l}\text { - Widely used global measure to assess } \\
\text { functional capability. } \\
\text { - Used both in clinical oncology and } \\
\text { clinical trials. }\end{array}$ \\
\hline $\begin{array}{l}\text { Brief Fatigue Inventory. }{ }^{23} \text { Nine-item single- } \\
\text { dimension report of subjective fatigue. }\end{array}$ & $\begin{array}{l}\text { Reliability: } r=0.88, P \leq 0.00 \mathrm{I} \\
\text { Internal consistency: } \alpha=0.96\end{array}$ & $<2$ minutes & $\begin{array}{l}\text { - Correlates well with measures of } \\
\text { performance status, physiologic markers } \\
\text { of anemia, and nutritional status. } \\
\text { - Provides a global fatigue score. }\end{array}$ \\
\hline $\begin{array}{l}\text { EORTC-QLC } 30 .{ }^{25} \text { Thirty-item health- } \\
\text { related quality-of-life questionnaire that } \\
\text { measures five functions (physical, role, } \\
\text { cognitive, emotional, and social) and } \\
\text { nine symptoms (fatigue, pain, nausea } \\
\text { and vomiting, dyspnea, loss of appetite, } \\
\text { insomnia, constipation, diarrhea, and } \\
\text { financial difficulties). }\end{array}$ & $\begin{array}{l}\text { Validity: three approaches used: } \\
\text { I. interscale correlations statistically } \\
\text { significant; } \\
\text { 2. performance status items } \\
\text { statistically significant in the } \\
\text { expected direction; and } \\
\text { 3. functional and symptom measures } \\
\text { were discriminatory. } \\
\text { Internal consistency: } \alpha=0.70 \text {. }\end{array}$ & $\sim 10-15$ minutes & $\begin{array}{l}\text { - A comprehensive measure of quality } \\
\text { of life. } \\
\text { - Strong prognostic value. }\end{array}$ \\
\hline
\end{tabular}

Abbreviations: ECOG, Eastern Cooperative Oncology Group; EORTC-QLC30, European Organization of Research and Treatment-Related Quality of Life Core Questionnaire; MCS, Mental Component Score; PCS, Physical Component Score; SF-12, Short-Form I2; SF-36, Short-Form 36. 
activity should consult their physician or oncology provider before participating in an exercise program.

The ONS PEP guidelines and the NCCN both recommend including physical activity in the treatment plan for CRF. ${ }^{12,14}$ Low-intensity aerobic exercise has been studied extensively, mainly in breast, prostate, and hematological malignancy patients, ${ }^{37,38}$ and significant improvements in fatigue and pain levels were demonstrated. A progressive home walking program, which emphasized starting at low intensity and gradually increasing distance and/or walking time, was well tolerated and significantly reduced fatigue and pain levels in both postoperative resected breast cancer and pancreas cancer patients..$^{21,36}$ Patients in the walking intervention group had higher self-reported quality-of-life scores than those in the control group. ${ }^{21}$ However, neither the most effective type of exercise nor the frequency and intensity needed to optimally reduce CRF have been determined. Before initiating any exercise program, home-based, gymbased, or part of a cancer rehabilitation program, the level of deconditioning present must be assessed. ${ }^{39}$ Areas to consider are: pre-diagnosis level of activity, current ability to accomplish activities of daily living, and physical impediments that would warrant exercise modifications. The recent ASCO CRF guidelines state that low-intensity exercise can be initiated without physician approval, but very deconditioned individuals will benefit from referral to a physical rehabilitation program. ${ }^{13}$ Cancer rehabilitation is a growing field that recognizes cancer as an acute and chronic condition and seeks to minimize the impact of cancer treatment and disease-related side effects. ${ }^{34}$ The American College of Sports Medicine established a certification program for fitness experts working with cancer survivors. ${ }^{39}$ These types of programs, when administered to cancer survivors, can help reduce $\mathrm{CRF}$ and the decline in functional capacity that often accompanies CRF. Longitudinal studies documenting improvement in CRF and other cancer side effects in cancer rehabilitation programs are needed. Based on the multitude of available evidence, health care providers should feel comfortable encouraging patient participation in physical activity during the cancer journey.

\section{Patient and family education and self-care strategies}

All cancer patients and their families should receive education and counseling about the association between cancer, cancer therapy, and CRF. ${ }^{13}$ Many patients are reluctant to mention their fatigue or lack of energy issues to their providers because they believe that this is to be expected or that it is not important or related to their cancer. Patients may worry that their treatment will be halted or delayed if they report fatigue. ${ }^{3}$ Of note, $78 \%$ of cancer patients queried reported an increased need for sleep, typically requiring an additional 3 hours of sleep per day. ${ }^{6}$ Patients should be given information about self-care strategies that may help them manage their CRF. These strategies include: keeping a daily log of symptoms and feelings, recording fatigue level (0-10 scale), and tracking activities of daily living, sleep/nap schedule, and movement (exercise). Energy conservation is important and can be enhanced by setting daily priorities for what needs to be accomplished and postponing nonessential duties, maintaining a realistic pace, delegating activities if possible, scheduling activities for times of peak energy, and limiting daytime naps so as not to interfere with nighttime sleep. Intentionally promoting distracting activities such as listening to music, playing card or board games, watching educational television, and reading can divert attention from CRF and energize patients. ${ }^{3,32}$

Fatigue and depression are often reported as concurrent symptoms, ${ }^{40}$ but patients and their families should be aware that they are independent conditions; one does not predict the other. Patients should be informed that needing more sleep is usual and not a cause in itself for worry. However, ongoing sleep disturbances may be a sign of depression. Cancer patients have been observed to have prevalence rates of major depression that are higher than in the general population. ${ }^{41}$ Depression rates are highest for those with pancreatic cancer and oropharyngeal cancers. ${ }^{41}$ Persistent depression should be evaluated and treated by a mental health professional. Medical oncologists, palliative care specialists, and psychiatric social workers, as well as oncology clinical nurse specialists, nurse practitioners, and physician assistants, are positioned to assist patients with uncomplicated emotional issues, anxiety, and depression. Depending on the American state and the country in which one practices, physicians, psychiatric clinical nurse specialists, and nurse practitioners will be able to prescribe antidepressant medications when indicated.

\section{Psychologically based interventions}

Psychologically based interventions (also called psychosocial interventions) include methods that focus on cognition, coping skills, and behavior. Jacobsen et al and Goedendorp et al reviewed psychologically based interventional studies and concluded that interventions that alter cognition, improve coping skills, and change behaviors are more effective in decreasing CRF than physical activity and medications. ${ }^{27,42}$ Moreover, the ONS PEP guidelines state that psychoeducational interventions are "likely to be effective" 
based on more than 12 RCTs and quasi-experimental studies that have demonstrated positive effects on fatigue outcomes. ${ }^{34}$ In some studies, CRF was not improved but other symptoms, such as psychological issues, activity levels, and sleep quality, did improve. Psychological strategies that were found to be beneficial were: cognitive behavioral therapy, group psychotherapy, and psychoeducational and supportive-expressive techniques. They determined that the most important elements to incorporate in the treatment plan were patient education about the nature of CRF and self-care techniques to conserve energy and boost energy, as well as activity management that focuses on balancing activity and rest intervals. Coping strategies to lessen one's focus on CRF were also beneficial.

One example of an effective psychologically based intervention for cancer therapy-related fatigue was recently reported by Ream et al. ${ }^{43}$ They determined that CRF worsened the week following chemotherapy and that it became cumulative over the course of chemotherapy, often resulting in being bedridden by the end of treatment. A telephone version of Beating Fatigue, a psychologically based intervention for CRF that used a trained cancer nurse, was implemented. The intervention consisted of providing patients with a publication that addressed coping with fatigue, facilitating self-evaluation, and establishing personal goals and included structured telephone interviews. The researchers found a statistically significant reduction in fatigue intensity and fatigue-associated distress in those who participated in the intervention compared to those who did not participate. One's sense of self-efficacy in managing their fatigue and anxiety was also improved. Of note, however, depression did not improve with the intervention. A subset of patients in the study felt that reflecting on their CRF and keeping a daily log of fatigue and associated feelings increased their awareness of CRF, which in turn allowed them to take control. The telephone call itself from a trained cancer nurse had a therapeutic benefit. The technique of motivational interviewing which emphasizes the benefits of managing CRF through maintaining and enhancing one's physical activity was utilized in the study and provides a framework for assisting patients with CRF during chemotherapy.

An example of supportive-expressive therapy is professional or self-help support groups. Group-based interventions can significantly impact fatigue. Many self-help groups are available via the Internet. In 2008, there were more than 600 online breast cancer support groups with more than 1 million followers. Millions of people rely on the Internet for information about cancer and to identify resources for treatment and symptom management and for social networking with other cancer survivors, ${ }^{44}$ despite ongoing concerns about monitoring the content of websites. In 2013 , it was estimated that $85 \%$ of American adults use the Internet, ${ }^{44}$ and in $2008,60 \%$ of patients relied on the Internet as their first source of information. ${ }^{45}$ The American Cancer Society piloted an online cancer fatigue class in $2010^{46}$ which was positively perceived, and significant improvements in fatigue knowledge were demonstrated post hoc. Yun et al demonstrated the efficacy of an RCT of a web-based CRF education program for 273 long-term cancer survivors (off therapy for 24 months), who were still experiencing fatigue. ${ }^{47}$ The 12 -week course, Health Navigation, covered six strategic areas: energy conservation, physical activity, nutrition, sleep hygiene, pain control, and distress management. Patients in the intervention group experienced clinically meaningful improvement in anxiety, severe fatigue, and global quality of life. Those with the most severe symptoms experienced the greatest improvement. This study, the first to use a web-based program for CRF, indicates that the Internet is an important route for successful self-management of CRF.

The following four complementary interventions are now recommended in the 2014 ONS PEP guidelines due to accumulation of study evidence demonstrating their effectiveness in reducing CRF: 1) progressive muscle relaxation and relaxation breathing with or without guided imagery or distraction; 2) yoga practices; 3) meditation; and 4) mindfulness stress reduction. ${ }^{34}$ Many patients are eager to try these techniques, which are increasingly available even in rural areas and can be accessed by the Internet as well. Although there is evidence that acupuncture, acupressure, and self-acupuncture are effective in reducing CRF and improving quality of life, ${ }^{48}$ caution is recommended when advising patients regarding these therapies as many of the study sample sizes were small, with short follow-up times, and with notable variations in techniques used by the acupuncturists. Preliminary data indicate that expressive writing, biofeedback, viewing art, listening to music, animal therapy, cranial stimulation, exposure to nature, distraction, tai chi, qigong, aromatherapy, lavender foot soaks, and reflexology are promising in reducing CRF. ${ }^{34}$ Morning exposure to bright light also appears promising as an adjunct therapy for CRF. ${ }^{49}$ Four studies have demonstrated lessened CRF and improved quality of life in study populations that include cancer patients with mixed diagnoses. ${ }^{49-52}$ More rigorous study design and methodology are needed before these strategies are recommended as part of the ONS PEP guidelines. 


\section{Nutrition and supplements}

Maintaining adequate nutrition can be a difficult for patients undergoing active adjuvant cancer therapy. Anorexia, nausea and vomiting, bowel dysregulation, stomatitis, and alterations in one's sense of taste or smell all lessen the appeal of food and decrease the pleasure of eating. Maintaining energy balance and preventing excessive weight loss are the goals for those in active cancer treatment and may lessen therapyrelated adverse effects. The American Cancer Society recommends smaller, more frequent meals to increase food intake. ${ }^{53}$ Commercially prepared or homemade nutritious snacks and drinks may be helpful and are soundly recommended.

Patients frequently ask their health care providers about the use of vitamins and nutritional supplements. There is controversy regarding the role of antioxidant supplements. Antioxidants repair cellular oxidative damage to cells, including cancer cells. Melatonin may enhance the effect of chemotherapy. There is not a clear answer regarding the use of antioxidants, therefore patients are cautioned not to exceed the daily recommended intake of vitamins $\mathrm{C}$ and $\mathrm{E} .{ }^{53}$ A number of nutritional supplements and herbal remedies have been evaluated to assess their efficacy in reducing CRF. These include levocarnitine, vitamin supplements, highdose vitamin $\mathrm{C}$, lechtin-standardized mistletoe, megestrol with omega-3 fatty acids, protein supplements, guaran, valerian, and Chinese herbal medicines. The data indicate that improvement in CRF was inconsistent and many of the trials described in this review article may have been biased from nonrandomized study designs, open-label drug use, small samples, and testing multiple secondary endpoints. ${ }^{14}$ Therefore, these supplements are not recommended at this time to be used for reduction of CRF. An 8-week course of Wisconsin ginseng (2,000 $\mathrm{mg}$ daily) was well tolerated in a double-blind placebo-controlled trial and improved CRF. ${ }^{54}$ The ONS PEP guidelines have termed ginseng as "likely to be effective" in reducing CRF. ${ }^{14}$

\section{Pharmacologic management}

The effectiveness of pharmacologic (prescription medications) treatment for CRF has been limited to specific patient populations and has been generally disappointing. Patients experiencing the most severe fatigue and greater constellation of symptoms (pain, nausea, anorexia, depression, anxiety, or sleep disturbances) have derived the most benefit from stimulant, nonstimulant, and erythropoiesis-stimulating agents, though study results are mixed. The ONS PEP guidelines term pharmacological interventions "effectiveness not established". ${ }^{14}$

\section{Psychostimulants}

The use of methylphenidate, a psychostimulant used in the treatment of attention-deficit disorder, has been the subject of controversy for a number of years. It is the most studied pharmacological agent for treatment of CRF. Both methylphenidate and dexamphetamine derive their benefit from decreasing drowsiness and increasing activity. Bruera et al in 2003 compared methylphenidate ( $5 \mathrm{mg}$ every 2 hours) to placebo and used the FACIT-Fatigue Scale to measure CRF levels. ${ }^{55}$ Fatigue intensity improved in both groups over a 7-day study period but there were no differences in fatigue scores, suggesting a positive placebo effect. A 2010 RTC using long-acting methylphenidate also did not find a benefit for CRF patients. ${ }^{56}$ Kerr et al found a decrease in fatigue with the use of methylphenidate, but five larger RCTs did not find a benefit. ${ }^{57}$ Minton et al conducted a systematic review and meta-analysis of four psychostimulant trials using methylphenidate and one with dexamphetamine for CRF in 2011 and concluded that there may a slight reduction in CRF with methylphenidate but that the potential side effects, adrenal suppression and alterations in bone metabolism, outweighed the benefits. ${ }^{16}$

Modafinil is another psychostimulant that has been used to treat CRF. Several RCTs have reported conflicting results. Spathis et al found no difference between the modafinil and the placebo groups in terms of CRF improvement. ${ }^{58} \mathrm{~A} 2010$ RCT of 877 cancer patients with hematologic malignancies, lung cancer, colorectal cancer, and gynecologic cancers found that $95 \%$ of the patients, when queried, expected to have fatigue while undergoing chemotherapy or radiation therapy. ${ }^{59}$ Patients were randomized to either the non-amphetamine stimulant (modafinil) group $(n=431)$ or the placebo group $(n=436)$. They found that modafinil was most effective in patients with the most severe fatigue levels $(>7 / 10)$. Further, their results confirmed other findings in studies of brain cancer and breast cancer patients, in that modafinil reduced fatigue intensity and lessened daytime sleepiness, but did not improve depression. These results suggest that while fatigue and depression often co-occur in cancer patients, the underlying bio mechanisms are not identical.

\section{Selective serotonin reuptake inhibitors}

The selective serotonin reuptake inhibitors (SSRIs), particularly paroxetine $\left(\right.$ Paxil $\left.^{\mathrm{TM}}\right)$, are often used in cancer patients experiencing CRF and depression. ${ }^{60}$ Paroxetine was previously found to be effective in treating depression and reducing hot flashes in women with breast cancer, but it had no significant effect on CRF. ${ }^{61}$ More recently, paroxetine has been shown 
to have weak estrogenic effects and behaves as an endocrine disrupter. ${ }^{62}$ About $70 \%$ of female breast cancers are sensitive to estrogen, and the use of paroxetine and other similar SSRIs could contribute to the development of breast cancer. ${ }^{61}$

In women already diagnosed and treated for estrogenpositive breast cancers, tamoxifen is used to reduce the risk of breast cancer recurrence. ${ }^{63}$ Some of these women are also treated with SSRIs for depression. Another SSRI risk is related to drug metabolism effects that arise when using the combination of an SSRI and tamoxifen. Both the SSRIs and tamoxifen are metabolized by cytochrome P450 2D6 (CYP2D6). SSRIs have the potential to inhibit CYP2D6 activity thereby reducing the effectiveness of tamoxifen. ${ }^{62}$ Lash et al evaluated the effect of the SSRI citalopram on tamoxifen. ${ }^{60,63}$ They concluded that citalopram has the least anti-CYP2D6 activity of the SSRIs and, in registry studies, it did not increase the risk of breast cancer recurrence. ${ }^{60,63}$ Providers considering use of SSRIs in women with estrogenpositive breast cancers should be familiar with these data and should avoid the use of known CYP2D6 inhibitors in hormone receptor-positive breast cancers.

\section{Corticosteroids}

Corticosteroids are the most used drug for relief of adverse symptoms in cancer patients, particularly those patients receiving palliative care, where the frequency of use is $32 \%-80 \%{ }^{64}$ The benefit from corticosteroids is derived from its anti-inflammatory properties and its modulatory effects on the proinflammatory cytokines (interleukins 6 and $1 \mathrm{~b}$, tumor necrosis factor- $\alpha$ ), prostaglandins, and dopamine. ${ }^{65}$

A few RCTS conducted in the 1980s and 1990s indicated that low-dose methylprednisolone (32 $\mathrm{mg}$ per day) produced modest reduction in fatigue. ${ }^{65}$ Unfortunately, many of these studies did not assess CRF as the primary outcome metric or did not use validated measurement tools to assess CRF. A $2013 \mathrm{RCT}$ compared dexamethasone (4 $\mathrm{mg}$ twice a day) to placebo in 83 advanced-stage cancer patients ${ }^{66}$ and found that both groups had significant improvement in fatigue scores, but only the dexamethasone group experienced improvement in physical distress scores. These results should be interpreted with cautious optimism favoring the use of steroids in palliative care cancer patients.

Progestational steroids have been used to treat anorexia, cachexia, nausea, and fatigue based on older work. Minton et al reviewed four studies on progestational steroids used for anorexia and cachexia; fatigue was a secondary outcome. A significant difference was found between pregestational steroids and placebo in improving CRF. ${ }^{15}$

\section{Erythropoiesis-stimulating agents}

Erythropoiesis-stimulating agents (ESAs) are effective for treating anemias in cancer patients and may reduce fatigue and improve other symptoms, such as shortness of breath, when the hemoglobin is less than $10 \mathrm{~g} / \mathrm{dL} .{ }^{67}$ The use of ESAs has been documented to significantly improve CRF and, in some studies, quality of life, when a hemoglobin of $11-12 \mathrm{~g} / \mathrm{dL}$ is achieved. ${ }^{15,67}$ Concerns have been raised over the safety of ESAs as an increased risk of thromboembolic complications and death has been observed in some cancer patients. ${ }^{67}$ ASCO and the American Society of Hematology recommend that ESAs should not be used unless cancer patients are receiving concurrent chemotherapy, except in certain circumstances, such as decreased cardiopulmonary reserve in a patient with a hemoglobin less than $10 \mathrm{~g} / \mathrm{dL} .{ }^{68}$ Therefore, while the use of ESAs is appropriate when the hemoglobin is below the recommended level, its use is discouraged for milder forms of anemia and in patients with known thromboembolic issues.

\section{Summary: implications for practice}

$\mathrm{CRF}$, a multidimensional condition characterized by subjective findings such as tiredness, lack of energy, and weakness, is generally under-recognized in clinical practice and therefore undertreated. The best therapy for CRF is neither obvious nor intuitive. A wide range of strategies have been employed from pharmacologically based to nonpharmacological interventions. A 2012 review of the literature evaluated over 170 studies of cancer patients with fatigue. ${ }^{69}$ Exercise had the strongest empirical evidence, with physical activity providing moderate benefit in CRF patients. Psychological interventions, particularly those that provided patient education about CRF, coaching on self-care measures and activity management, showed moderate patient benefit. Enthusiasm for pharmacologic measures is limited, with much conflicting evidence about currently available medications. It is challenging to recruit fatigued cancer patients for clinical and intervention trials and difficult to conduct the studies. Many studies have only included patients with moderate fatigue and not those with severe fatigue, thereby excluding those in most need. There is a critical need for basic research that elucidates the underlying mechanisms of CRF.

Providers should gain familiarity with the NCCN and ONS PEP guidelines for management of CRF, as well monitor the medical and nursing literature for published studies of advances in the treatment of CRF. Whenever clinical trials or drug trials are available at an accessible institution, cancer patients with CRF should be referred and encouraged to 
participate in those investigations. Management of patients with CRF, whether they have active disease or are in diseasefree remission, should be individualized using the available national and oncologic societal guidelines, based on the individual's overall health status, type and stage of cancer, therapy received, and their personal preferences. Survivorship care plans should address CRF and related issues of concern. As more cancer survivors transition from specialized oncologic care to community physicians and nurse practitioners for their care, it is imperative to translate knowledge of the late and long-term effects of cancer and cancer therapy into useful information for providers. Perhaps more important is to provide patients and their families with lifestyle education and guidance programs on the benefits of diet, exercise, and psychosocial interventions to effectively manage CRF and other symptoms to enhance survival and quality of life.

\section{Disclosure}

The authors report no conflicts of interest in this work.

\section{References}

1. American Cancer Society. Cancer Treatment and Survivorship Facts and Figures 2012-2013. Atlanta: American Cancer Society; 2012. Available from: http://www.cancer.org/acs/groups/content/@ epidemiologysurveilance/documents/document/acspc-033876.pdf. Accessed March 14, 2015.

2. Morgan MA. Cancer survivorship: history, quality-of-life issues, and the evolving multidisciplinary approach to implementation of cancer survivorship care plans. Oncol Nurs Forum. 2009;36(4):429-436.

3. Berger AM, Abernethy AP, Atkinson A, et al. Cancer-related fatigue. $J$ Natl Compr Canc Netw. 2010;8(8):904-931.

4. International Classification of Diseases, Tenth Revision, Clinical Modification (ICD-10-CM) Official Guidelines for Coding and Reporting. Available from: http:/www.cdc.gov/nchs/data/icd/ICD10cmguidelines_2015\%20 9_26_2014.pdf. Accessed January 25, 2015.

5. Jean-Pierre P, Figueroa-Moseley CD, Kohli S, Fiscella K, Palesh OG, Morrow GR. Assessment of cancer-related fatigue: implications for clinical diagnosis and treatment. Oncologist. 2007;12 Suppl 1:11-21.

6. Curt GA, Breitbart W, Cella D, et al. Impact of cancer-related fatigue on the lives of patients: new findings from the Fatigue Coalition. Oncologist. 2000;5(5):353-360.

7. Piper BF, Cella D. Cancer-related fatigue: definitions and clinical subtypes. J Natl Compr Canc Netw. 2010;8:958-966.

8. Winningham ML. Strategies for managing cancer-related fatigue syndrome. Cancer. 2001;92(4 Suppl):988-997.

9. Dimeo F, Rumberger B, Keul J. Aerobic exercise as therapy for cancer fatigue. Med Sci Sports Exerc. 1998;30:475-478.

10. Gutstein HB. The biologic basis of fatigue. Cancer. 2001;92(6 Suppl): 1678-1683.

11. Howell D, Keller-Olaman S, Oliver TK, et al. A pan-Canadian practice guideline and algorithm: screening, assessment, and supportive care of adults with cancer-related fatigue. Curr Oncol. 2013;20:e233-e246.

12. NCCN Clinical Practice Guidelines. Cancer-Related Fatigue. Version 1.2014. Available from: http:/www.nccn.org/professionals/ physician_gls/pdf/fatigue.pdf. Accessed January 25, 2015.

13. Bower JE, Bak K, Berger A, et al; American Society of Clinical Oncology. Screening, assessment, and management of fatigue in adult survivors of cancer: an American Society of Clinical oncology clinical practice guideline adaptation. J Clin Oncol. 2014;32(17):1840-1850.
14. Mitchell SA, Clark JC, DeGennaro RM, et al. Fatigue [webpage on the Internet]. Pittsburgh: Oncology Nursing Society; 2011-2014. Available from: http://www.ons.org/practice-resources/pep/fatigue. Accessed January 26, 2015.

15. Minton O, Richardson A, Sharpe M, Hotopf M, Stone P. Drug therapy for the management of cancer-related fatigue. Cochrane Database Syst Rev. 2010;(7):CD006704

16. Minton O, Richardson A, Sharpe M, Hotopf M, Stone PC. Psychostimulants for the management of cancer-related fatigue: a systematic review and meta-analysis. J Pain Symptom Manage. 2011;41(4):761-767.

17. Roe H, Lennan E. Role of nurses in the assessment and management of chemotherapy-related side effects in cancer patients. Nursing (Auckl). 2014;4:103-115.

18. Luthy C, Cedraschi C, Pugliesi A, et al. Patients' views about causes and preferences for the management of cancer-related fatigue-a case for non-congruence with the physicians? Support Care Cancer. 2011;19(3): $363-370$.

19. Lis CG, Rodeghier M, Grutsch JF, Gupta D. Distribution and determinants of patient satisfaction in oncology with a focus on health related quality of life. BMC Health Serv Res. 2009;9:190.

20. James S, Wright P, Scarlett C, Young T, Jamal H, Verma R. Cancerrelated fatigue: results from patient experience surveys undertaken in a UK regional cancer center. Support Care Cancer. Epub December 23, 2014.

21. Yeo TP, Burrell SA, Sauter PK, et al. A progressive postresection walking program significantly improves fatigue and health-related quality of life in pancreas and periampullary cancer patients. J Am Coll Surg. 2012;214:463-477.

22. Yellen SB, Cella DF, Webster K, Blendowski C, Kaplan E. Measuring fatigue and other anemia-related symptoms with the Functional Assessment of Cancer Therapy (FACT) measurement system. J Pain Symptom Manage. 1997;13(2):63-74

23. Mendoza TR, Wang XS, Cleeland CS, et al. The rapid assessment of fatigue severity in cancer patients: use of the Brief Fatigue Inventory. Cancer. 1999;85(5):1186-1196.

24. Piper BF, Dibble SL, Dodd MJ, Weiss MC, Slaughter RE, Paul SM. The revised Piper Fatigue Scale: psychometric evaluation in women with breast cancer. Oncol Nurs Forum. 1998;25(4):677-684.

25. Aaronson NK, Ahmedzai S, Bergman B, et al. The European Organization for Research and Treatment of Cancer QLQ-C30: a quality-of-life instrument for use in international clinical trials in oncology. J Natl Cancer Inst. 1993;85(5):365-376.

26. Piper BF, Dodd MJ, Ream E, et al. Improving the clinical measurement of cancer-related fatigue. In: Better Health Through Nursing Research: International State of the Science. Washington, DC: American Nurses Association; 1999:99.

27. Goedendorp MM, Gielissen MF, Verhagen CA, Bleijenberg G. Psychosocial interventions for reducing fatigue during cancer treatment in adults. Cochrane Database Syst Rev. 2009;(1): CD006953.

28. Ware JE Jr, Sherbourne CD. The MOS 36-item short-form health survey (SF-36). I. Conceptual framework and item selection. Med Care. 1992;30(6):473-483.

29. Ware J Jr, Kosinski M, Keller SD. A 12-item Short-Form Health Survey: construction of scales and preliminary tests of reliability and validity. Med Care. 1996;34(3):220-233.

30. Oken MM, Creech RH, Tormey DC, et al. Toxicity and response criteria of the Eastern Cooperative Oncology Group. Am J Clin Oncol. 1982;5:649-655.

31. Torrance GW, Feeny D, Furlong W. Visual analog scales: do they have a role in the measurement of preferences for health states? Med Decis Making. 2001;21(4):329-334.

32. Wanchai A, Armer JM, Stewart BR. Nonpharmacologic supportive strategies to promote quality of life in patients experiencing cancer-related fatigue: a systematic review. Clin J Oncol Nurs. 2011;15(2):203-214. 
33. Blackwell DL, Lucas JW, Clarke TC. Summary health statistics for US adults: national health interview survey, 2012. Vital Health Stat 10. 2014;(260):1-161.

34. Mitchell SA, Hoffman AJ, Clark JC, et al. Putting evidence into practice: an update of evidence-based interventions for cancer-related fatigue during and following treatment. Clin J Oncol Nurs. 2014;18 Suppl:38-58.

35. Cramp F, Byron-Daniel J. Exercise for the management of cancer-related fatigue in adults. Cochrane Database Syst Rev. 2012;11:CD006145.

36. Yeo TP. Exercise improves fatigue during and after breast and prostate treatment, with benefits seen for aerobic exercise. Evid Based Nurs. 2013;16(4):101-102.

37. Gracey JH, Watson M, Payne C, Rankin J, Dunwoody L. Translational research: 'Back on Track', a multiprofessional rehabilitation service for cancer-related fatigue. BMJ Support Palliat Care. Epub December 19, 2014.

38. Mock V, Pickett M, Ropka ME, et al. Fatigue and quality of life outcomes of exercise during cancer treatment. Cancer Pract 2001;9(3):119-127.

39. Franklin D, Delengowski AM, Yeo TP. Facing forward: meeting the rehabilitation needs of cancer survivors. Oncology (Williston Park). 2010;24(10 Suppl):21-23, 29-32.

40. Visser MR, Smets EM. Fatigue, depression and quality of life in cancer patients: how are they related? Support Care Cancer. 1998;6: 101-108.

41. Musselman DL, Miller AH, Porter MR, et al. Higher than normal plasma interleukin- 6 concentrations in cancer patients with depression preliminary findings. Am J Psychiatry. 2001;158(8):1252-1257.

42. Jacobsen PB, Donovan KA, Vadaparampil ST, Small BJ. Systematic review and meta-analysis of psychological and activity-based interventions for cancer-related fatigue. Health Psychol. 2007;26:660-667.

43. Ream E, Richardson A, Alexander-Dann C. Supportive intervention for fatigue in patients undergoing chemotherapy: a randomized controlled trial. J Pain Symptom Manage. 2006;31:148-161.

44. Wagner-Johnston N. Computer/online-mediated social support for cancerrelated fatigue. J Natl Compr Canc Netw. 2013;11(10):1211-1217.

45. Hesse BW, Moser RP, Rutten LJ. Surveys of physicians and electronic health information. $N$ Engl J Med. 2010;362:859-860.

46. Smith T, Richardson K, Crammer C, et al. Theory-based evaluation of an online cancer fatigue class. $J$ Cancer Educ. 2010;25:422-430.

47. Yun YH, Lee KS, Kim YW, et al. Web-based tailored education program for disease-free cancer survivors with cancer-related fatigue: a randomized controlled trial. J Clin Oncol. 2012;30:1296-1303.

48. Molassiotis A, Bardy J, Finnegan-John J, et al. Acupuncture for cancerrelated fatigue in patients with breast cancer: a pragmatic randomized controlled trial. J Clin Oncol. 2012;30(36):4470-4476.

49. Ancoli-Israel S, Rissling M, Neikrug A, et al. Light treatment prevents fatigue in women undergoing chemotherapy for breast cancer. Support Care Cancer. 2012;20:1211-1219.

50. Jeste $\mathrm{N}$, Lui L, Rissling M, et al. Prevention of quality-of-life deterioration with light therapy is associated with changes in fatigue in women with breast cancer undergoing chemotherapy. Qual Life Res. 2013;22:1239-1244.

51. Neikrug AB, Rissling M, Trofimenko V, et al. Bright light therapy protects women from circadian rhythm desynchronization during chemotherapy for breast cancer. Behav Sleep Med. 2012;10:202-216.

52. Redd WH, Valdimarsdottir H, Wu LM, et al. Systematic light exposure in the treatment of cancer-related fatigue: a preliminary study. Psychooncology. 2014;23:1431-1434.

53. Brown JK, Byers T, Doyle C, et al; American Cancer Society. Nutrition and physical activity during and after cancer treatment: an American Cancer Society guide for informed choices. CA Cancer J Clin. 2003;53(5):268-291.
54. Barton DL, Liu H, Dakhil SR, et al. Wisconsin Ginseng (Panax quinquefolius) to improve cancer-related fatigue: a randomized, double-blind trial, N07C2. J Natl Cancer Inst. 2013;105:1230-1238.

55. Bruera E, Driver L Barnes EA, et al. Patient-controlled methylphenidate for the management of fatigue in patients with advanced cancer: a preliminary report. J Clin Oncol. 2003;21(23):4439-4443.

56. Moraska AR, Sood A, Dakhil SR, et al. Phase III, randomized doubleblind, placebo-controlled study of long-acting methylphenidate for cancer-related fatigue: North Central Cancer Treatment Group NCCTGN05C7 Trial. J Clin Oncol. 2010;28(23):3673-3679.

57. Kerr CW, Drake J, Milch RA, et al. Effects of methylphenidate on fatigue and depression: a randomized, double-blind, placebo-controlled trial. J Pain Symptom Manage. 2012;43(1):68-77.

58. Spathis A, Dhillan R, Booden D, Forbes K, Vrotsou K, Fife K. Modafinil for the treatment of fatigue in lung cancer: a pilot study. Palliat Med. 2009;23:325-331.

59. Jean-Pierre P, Morrow GR, Roscoe JA, et al. A phase 3 randomized, placebo-controlled, double-blind, clinical trial of the effect of modafinil on cancer-related fatigue among 631 patients receiving chemotherapy: a University of Rochester Cancer Center Community Clinical Oncology Program Research base study. Cancer. 2010;116:3513-3520.

60. Lash TL, Cronin-Fenton D, Ahern TP, et al. Breast cancer recurrence risk related to concurrent use of SSRI antidepressants and tamoxifen. Acta Oncol. 2010;49:305-312.

61. Weitzner MA, Moncello J, Jacobsen PB, Minton S. A pilot trial of paroxetine for the treatment of hot flashes and associated symptoms in women with breast cancer. J Pain Symptom Manage. 2002;23:337-345.

62. Chen S, Zhou D, Hsin LY, et al. AroER tri-screen is a biologically relevant assay for endocrine disrupting chemicals modulating the activity of aromatase and/or the estrogen receptor. Toxicol Sci. 2014;139(1): 198-209.

63. Lash TL, Pedersen L, Cronin-Fenton D, et al. Tamoxifen's protection against breast cancer recurrence is not reduced by concurrent use of the SSRI citalopram. Br J Cancer. 2008;99:616-621.

64. Henry NL, Stearns V, Flockhart DA, Hayes DF, Riba M. Drug interactions and pharmacogenomics in the treatment of breast cancer and depression. Am J Psychiatry. 2008;165(10):1251-1255.

65. Yennurajalingam $S$, Bruera E. Review of clinical trials of pharmacologic interventions for cancer-related fatigue: focus on psychostimulants and steroids. Cancer J. 2014;20(5):319-324.

66. Yennurajalingam S, Frisbee-Hume S, Palmer JL, et al. Reduction of cancer-related fatigue with dexamethasone: a double-blind, randomized, placebo-controlled trial in patients with advanced cancer. J Clin Oncol. 2013;31:3076-3082.

67. Tonelli M, Hemmelgarn B, Reiman T, et al. Benefits and harms of erythropoiesis-stimulating agents for anemia related to cancer: a metaanalysis. CMAJ. 2009;180(11):E62-E71.

68. Rizzo JD, Somerfield MR, Hagerty KL, et al; American Society of Clinical Oncology; American Society of Hematology. Use of epoetin and darbepoetin in patients with cancer: 2007 American Society of Clinical Oncology/American Society of Hematology clinical practice guideline update. J Clin Oncol. 2008;26:132-149.

69. Mitchell SA. Cancer-related fatigue: state of the science. PM R. 2010; 2(5):364-383.

70. Buccheri G, Ferringo D, Tamburini M. Karnofsky and ECOG performance status scoring in lung cancer: a prospective, longitudinal study of 536 patients from a single institution. Eur J Cancer. 1996;32A(7): $1135-1141$.

71. Conill C, Verger E, Salamero M. Performance status assessment in cancer patients. Cancer. 1990;65:1864-1866. 
Nursing: Research and Reviews

Dovepress

\section{Publish your work in this journal}

Nursing: Research and Reviews is an international, peer-reviewed, open access journal publishing original research, reports, reviews and commentaries on all aspects of nursing and patient care. These include patient education and counselling, ethics, management and organizational issues, diagnostics and prescribing, economics and

resource management, health outcomes, and improving patient safety in all settings. The manuscript management system is completely online and includes a very quick and fair peer-review system. Visit http://www.dovepress.com/testimonials.php to read real quotes from published authors.

Submit your manuscript here: http://www.dovepress.com/nursing-research-and-reviews-journal 